\title{
$\mathrm{HEVC}$ 엔트로피 부호화를 고려한 비균등 양자화 방법
}

\author{
권 령 희 ${ }^{\mathrm{a})}$, 한 우 진), 이 영 렬(a)
}

\section{Non-fixed Quantization Considering Entropy Encoding in HEVC}

\author{
RyeongHee Gweon ${ }^{\text {a) }}$, Woo-Jin Han ${ }^{\text {b) }}$ and Yung-Lyul Lee ${ }^{\text {a) }}$ \\ 요 약
}

ITU-T VCEG과 ISO/IEC MPEG은 공동으로 JCT-VC(Joint Collaborative Team on Video Coding) 를 구성하여 차세대 비디오 코 덱 $\mathrm{HEVC}$ (High Efficiency Video Coding)에 대한 표준화를 진행하고 있다. $\mathrm{HEVC}$ 에서 사용되고 있는 양자화 및 역 양자화는 TU(Transform Unit)내 모든 위치의 변환계수에 동일한 크기의 양자화 및 역 양자화를 수행한다. TU내의 변환계수는 동일하게 분포되 어 있지 않으므로 모든 위치의 변환계수에 동일한 크기의 양자화 및 역 양자화를 수행하는 것은 비효율적이다. 또한 주사 순서상 뒤 쪽에 있는 양자화 된 계수는 엔트로피 부호화 방법상 비효율적 일 수도 있다. 이 논문에서는 엔트로피 부호화의 효율성을 고려하여 $\mathrm{TU}$ 내 변환계수의 위치에 따라 다른 크기의 양자화를 수행하여 성능을 향상시키는 알고리즘을 제시한다. 이 알고리즘의 원리는 양자 화 된 계수 분포의 통계적 특징에 따른 $\mathrm{TU}$ 의 주사 순서에 따라 다른 크기의 양자화 및 역 양자화를 수행하는 것이다. 이 알고리즘은 평균 Y BD-rate $0.34 \%$ 의 압축률 향상을 나타내었다.

\begin{abstract}
MPEG and VCEG have constituted a collaboration team called JCT-VC(Joint Collaborative Team on Video Coding) and have been developing HEVC(High Efficiency Video Coding) standard. All transform coefficients in a TU(Transform Unit) have been equally quantized according to the quantization and inverse quantization method which is used in HEVC standard. Such an equal quantization is not efficient because the transformed coefficients in the TU are not eqully distributed. Furthermore, the quantized coefficients which is positioned in later scanning order cannot be efficient due to the entropy scanning method. We suggest an algorithm that transform coefficients are quantized at different values according to the position in $\mathrm{TU}$ considering a scanning order of entropy encoding to improve the coding efficiency. The principle of this algorithm is that quantization and inverse quantization are carried out according to the scanning order which is in accordance with the statistical characteristic of distribution of quantized transform coefficients. The proposed algorithm shows on the average of $0.34 \% \mathrm{Y}$ BD-rate compression rate improvement.
\end{abstract}

Keyword : High Efficiency Video Coding, Non-fixed quantization, Scanning order, Entropy encoding

a) 세종대학교 컴퓨터공학과 DMS 연구실

DMS Lab. Dept. of Computer Engineering, Sejong University

b) 경원대학교 소프트웨어 설계· 경영학과

Dept. of Software Design \& Management, Kyungwon University

\# 교신저자 : 이영렬(yllee@sejong.ac.kr)

※본 연구는 지식경제부 및 정보통신산업진흥원의 대학 IT연구센터 지원

사업의 연구결과로 수행되었음(NIPA-2011-(C1090-1111-0001))

· 접수일(2011년10월7일),수정일(2011년11월14일),게재확정일(2011년11월14일)

\section{I. 서 론}

최근 ITU-T VCEG과 $\mathrm{ISO} / \mathrm{IEC} \mathrm{MPEG}$ 은 공동으로 JCT-VC(Joint Collaborative Team on Video Coding)를 구 성하였다. JCT-VC는 차세대 비디오 표준인 $\mathrm{HEVC}^{[1]}$ 를 개 발 중이며, 압축 효율을 높이는 많은 코딩 기술들이 채택 
되었다. $\mathrm{HEVC}$ 는 기존의 압축 표준들과 비교하여, 최대 $64 \times 64$ 블록 사이즈, 화면 내 예측 모드에서 확장된 방향 성을 가지는 AIP(Angular Intra Prediction) ${ }^{[2]}$, 향상된 개선 된 움직임 벡터 예측 방법 ${ }^{[3][4]}, 8 \mathrm{bit}$ 영상을 코덱 내에서 10bit로 증가시켜 코딩되는 IBDI(Internal Bit-Depth Increase $)^{[5][6[7]}$, 움직임 벡터 병합 ${ }^{[4]}, \mathrm{RDOQ}^{[8]}, \mathrm{ALF}^{[9]}, \mathrm{Cbf}$ Fast Mode ${ }^{[10]}$ 기술이 채택되었으며, H.264/MPEG-4 AVC 보다 2배 이상의 압축효율을 목표로 표준화가 진행 중이다.

HEVC의 부호화는 $64 \times 64$ 크기의 LCU(Largest Coding Unit)단위로 수행한다. 각 $\mathrm{LCU}$ 는 계층적 쿼드트리 구조 로 되어 있다. 하나의 $\mathrm{LCU}$ 는 네 개의 $\mathrm{CU}$ 로 쪼개어 지고 쪼개어진 각각의 $\mathrm{CU}$ 는 또다시 네 개의 $\mathrm{CU}$ 로 쪼개어 진 다. 쿼드트리의 깊이는 4 이며 최소 $8 \times 8$ 크기의 $\mathrm{CU}$ 로 쪼개 어 질 수 있다. 각 $\mathrm{LCU}$ 의 부호화는 각각의 역할 중심으로 $\mathrm{CU}$ (Coding Unit), PU(Prediction Unit), TU(Transform Unit)의 단위로 각각 율-왜곡 최적화를 수행한다. 이 중 TU 는 변환과 양자화를 수행하는 단위이며 계층적 쿼드트리의 형태로 이루어져 있다. TU의 크기는 최소 $4 \times 4$ 이며, 최대 $32 \times 32$ 이다. $\mathrm{TU}$ 는 $\mathrm{CU}$ 의 크기가 $2 \mathrm{Nx} 2 \mathrm{~N}$ 이라면, 깊이가 3 인 $2 \mathrm{Nx} 2 \mathrm{~N}, \mathrm{NxN},(1 / 2) \mathrm{Nx}(1 / 2) \mathrm{N}$ 크기까지 쪼개어 질 수 있다. 양자화는 기본적으로 예측하고 나서 남은 오차값을 변환 한 변환계수의 크기를 줄이기 위해서 양자화 TU내의 변환 계수를 테이블로 나누는 것이다. $\mathrm{HEVC}$ 의 양자화는 TU단 위로 휘도성분과 색차성분에 대해서 각각 수행되며 양자화 테이블과 역 양자화 테이블의 모든 위치가 같은 값들로 이 루어져 있으며 오로지 $\mathrm{QP}(\mathrm{Quantization} \mathrm{Parameter)값에} \mathrm{의}$ 해서만 달라진다. 표. 1은 $\mathrm{QP} \% 6$ 별 $\mathrm{Q}$ 값과 $\mathrm{IQ}$ 값을 보여준 다. Q값과 $\mathrm{IQ}$ 값은 양자화 할 때 쓰는 공식에 사용되며, $\mathrm{Q}$ 값 이 커질 수록 양자화를 작게 하게 되며, Q값이 6씩 커질 때마다 표. 1 의 $\mathrm{Q}$ 값에 2 를 나누어서 양자화한다. $\mathrm{HEVC}$ 의 양자화 기술로 RDOQ (Rate-distortion optimized quantization)[8]가 채택되었다. RDOQ란 TU 내 한 계수를 양자화 할 때, 다수의 계수 후보를 두고 에러 값과 엔트로피 코딩을 고려한 비트 수를 계산하여 율 왜곡 값이 가장 낮은 계수를 쓰는 방식이다. RDOQ는 채택될 당시 성능은 약 $\mathrm{Y} \mathrm{BD-rate}$ 평균 $-4.7 \%$ 정도 성과를 보였으나, 인코더의 계산복잡도를 평균 $31 \%$ 정도 증가시켰다. 본 논문에서는 TU 내의 양자화
된 계수의 주사 방식및 계수의 위치에 따라 양자화 테이블 과 역 양자화 테이블을 다르게 하여 시간은 동일하면서 성 능을 향상시키는 비균등 양자화 방법을 제안한다.

제 2장에서는 현재 $\mathrm{HEVC}$ 의 양자화 및 역 양자화 방법과 주사방식에 대해 설명하고, 제 3장에서는 제안하는 비균등 한 양자화 방법에 대해 설명한다. 제 3장에서는 제안하는 방법의 양자화방법이 어떻게 성능이 나오는지도 함께 설명 한다. 제 4장에서는 $\mathrm{HEVC}$ 의 참조 소프트웨어인 HM4. $0^{[11]}$ 을 기반으로 $\mathrm{HEVC}$ 의 양자화 및 역양자화 방법과 제안된 방법과의 성능 비교 결과를 제시한다. 제 4장에서 $\mathrm{RDOQ}$ 와 제안하는 방법의 실험결과와 성능과 부호화 시간의 차이를 설명하고 제 5 장에서 결론을 맺는다.

표 1. $\mathrm{QP}$ 값에 따른 $\mathrm{Q}$ 값과 $I Q$ 값

Table 1. $Q$ and $I Q$ according to $Q P$ value

\begin{tabular}{|c|c|c|c|c|c|c|}
\hline QP\%6 & 0 & 1 & 2 & 3 & 4 & 5 \\
\hline Q & 26214 & 23302 & 20560 & 18396 & 16384 & 14564 \\
\hline IQ & 40 & 45 & 51 & 57 & 64 & 72 \\
\hline
\end{tabular}

\section{HEVC의 양자화와 주사 방식}

\section{HEVC의 양자화 및 역 양자화}

양자화란 연속된 양을 일정한 구간으로 잘라 그 구간 내 에서는 동일한 양으로 간주하는 것이다. 통상적인 부호화 방법에 의하면 화면 내 혹은 화면 간 예측을 마치고 나서 남은 잔차블록을 이산여현변환(DCT : Digital Cosine Transform)과 같은 방법으로 변환하여 $\mathrm{DC}$ 쪽으로 에너지가 집중되어 있는 변환계수블록을 만든다. 양자화는 변환계수 블록의 에너지를 효율적으로 줄이기 위해서 양자화 테이블 로 나누는 것을 의미한다. 양자화는 손실이 발생하는 가장 근본적인 원인이다. 손실발생정도는 양자화 테이블 내 수 치에 따라 달라질 수 있다. 통상적인 부호화 방법은 이 양자 화 테이블의 수치를 양자화 파라미터(QP : Quantization Parameter)로 양자화 테이블의 값을 조절할 수 있다. QP값 이 높으면 변환 계수를 크게 양자화하고, 낮으면 작게 양자 
화 한다.

현재 $\mathrm{HEVC}$ 인코더에서는 화면 내 혹은 화면 간 예측과 변환을 수행한 이후에 인코더는 아래 식 (1)을 이용하여 변 환계수를 양자화하고, 그 결과로 나온 양자화된 계수는 주 사되어 엔트로피 부호화가 수행되는 한편 참조영상을 생성 하기 위해서 아래 식 (2)의 역 양자화 공식을 사용하여 역 양자화 된다 ${ }^{[13]}$.

$$
\begin{gathered}
\text { level }=\frac{\text { Coeff } \times Q_{Q P \% 6}+\text { offset }}{2^{21+\frac{Q P}{6}-\log _{2} N}} \\
\text { Coeff } Q=\frac{\text { level } \times I Q_{Q P \% 6} \times 2^{\frac{Q P}{6}}}{2^{\log _{2} N-1}}
\end{gathered}
$$

위의 식에서 level, Coeff, CoeffQ는 각각 양자화 된 계수, 변환계수, 역 양자화 된 변환계수를 의미한다. 또한 $\mathrm{N}$ 은
$\mathrm{TU}$ 의 한 변의 길이를 의미한다. offset은 양자화 과정에서 의 반올림으로 인한 오류와 데드존(Dead Zone)의 크기를 결정하는 요소이다.

위의 $\mathrm{Q}$ 와 $\mathrm{IQ}$ 는 각각 $\mathrm{Q}$ 값과 $\mathrm{IQ}$ 값을 의미한다. $\mathrm{Q}$ 값과 $\mathrm{IQ}$ 값은 표 1와 같이 $\mathrm{QP}$ 를 6으로 나눈 나머지 값 $(\mathrm{QP} \% 6)$ 에 따라 달라지나, $\mathrm{TU}$ 내 계수의 위치가 $\mathrm{DC}$ 쪽이든 $\mathrm{AC}$ 쪽이든 똑같은 $\mathrm{Q}$ 값과 $\mathrm{IQ}$ 값을 유지한다. 이는 양자화 테이블 내의 모든 값이 똑같으며. TU내 모든 위치의 계수에 동일한 크 기의 양자화와 역 양자화를 수행함을 의미한다. 하지만 변 환계수의 에너지는 $\mathrm{DC}$ 계수 쪽으로 집중되어 있으며 주관 적 화질에 대한 중요도 또한 높기 때문에, 위치에 따라 다른 크기의 양자화를 수행할 필요가 있다.

\section{HEVC의 주사 방식}

통상적인 부호화 방법에 의하면, 엔트로피 부호화를 수 행하기 위해서 트랜스폼 계수를 양자화시킨 이후에 양자화
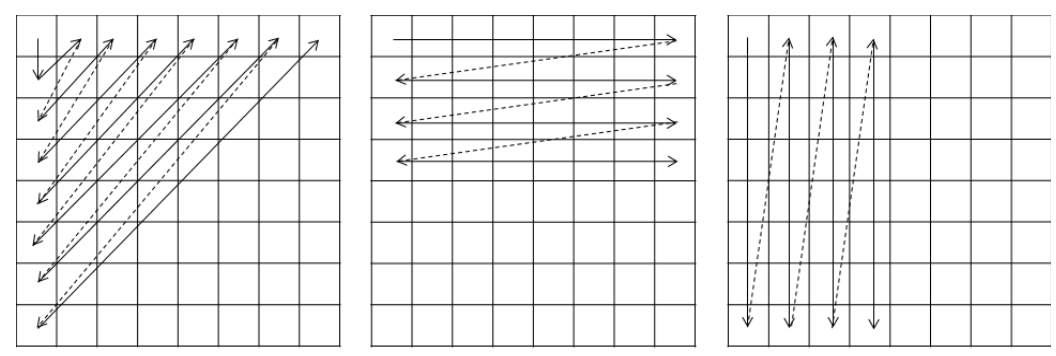

(a) 화면 내 예측 시 주사방식

(a) Scanning order for Intra prediction
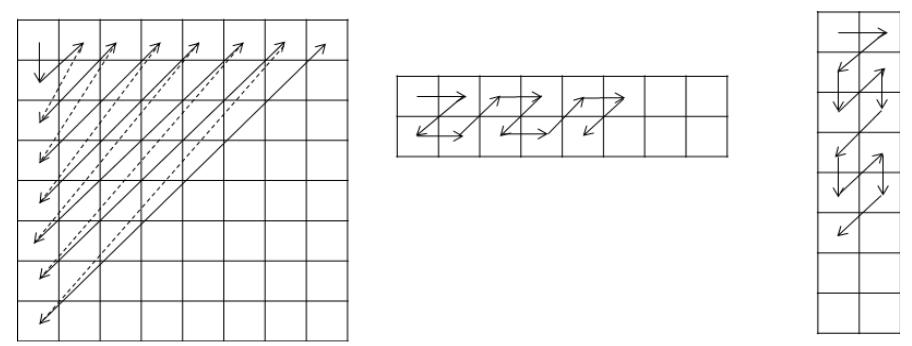

(b) 화면 간 예측시 주사방식

(b) Scanning order for Inter prediction

그림 1. HEVC의 주사방식

Fig. 1. Scanning order in HEVC 
된 계수들을 주사하여 일렬로 늘어놓는다. 엔트로피 부호 화의 결과로 적은 비트율이 나오게 하기 위해서는 0 이 아닌 양자화된 계수들이 주사 순서상 앞 쪽에 오게 하는 것이 유리하다.

그림 1 은 효율적인 $\mathrm{HEVC}$ 의 주사방식을 나타낸다. 화면 내 예측모드에서는 TU 내의 양자화 된 계수들을 화면 내 예측모드 정보에 따라 효율성을 고려하여 대각선방향 주사, 가로방향 주사, 세로방향 주사로 총 3 가지 방식을 사용하여 주사한다. 화면 내 예측은 예측방향에 따라 35 가지 모드가 있다. 그 중, $\mathrm{TU}$ 의 위 쪽에 있는 픽셀들로 부터 예측 값을 가지고 오는 예측모드로 선택된 경우에는 잔차신호가 세로 방향으로 상관도가 높게 나올 가능성이 높으므로, 양자화 된 계수가 위 쪽으로 집중되어 있을 가능성이 높다. 이 때는 위쪽에 있는 양자화된 계수부터 먼저 주사하는 가로방향 주사방식을 사용하는 것이 엔트로피 부호화 측면에서 효율 적이다. 반면에, $\mathrm{TU}$ 의 왼쪽에 있는 픽셀들로 부터 예측 값 을 가지고 오는 예측모드로 선택된 경우에는 잔차신호가 가로 방향으로 상관도가 높게 나올 가능성이 높으므로, 양 자화된 계수가 왼 쪽으로 집중되어 있을 가능성이 높다. 이 때는 왼 쪽에 있는 양자화된 계수부터 먼저 주사하는 세로 방향 주사방식을 사용하는 것이 엔트로피 부호화 측면에서 효율적이다 ${ }^{[14]}$.

화면 간 예측은 예측을 할 때 코딩 단위를 직사각형 형태 의 예측단위 $(\mathrm{PU})$ 로 나누어서 예측하기도 하고, 정사각형 PU로 나누어서 예측하기도 한다. H.264/AVC와는 달리 $\mathrm{HEVC}$ 는 $2 \mathrm{Nx}(1 / 2) \mathrm{N}$ 형태의 변환기술을 사용한다. 직사각 형의 예측단위로 예측을 했을 경우 이러한 직사각형 형태 로 변환한다. 정사각형 형태의 변환 및 양자화를 수행할 시 에는 대각선방향의 주사방식을 사용하고, 비정사각형 변환

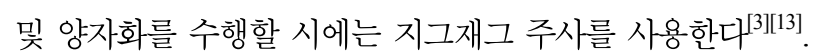

\section{III. 제안된 비균등 양자화 방법}

본 논문에서는 압축 효율을 높이기 위해서 주사 순서에 따라 트랜스폼 도메인을 두 영역으로 나눠서 양자화 크기 를 다르게 하는 방법을 제안한다. TU의 모든 변환계수에
동일한 크기로 양자화 시킨다면 주사 순서상 뒤 쪽에 0 이 아닌 절대값이 적은 양자화된 계수가 나타날 수 있다. 주사 순서상 뒤쪽에 있는 변환계수들은 크게 양자화 한다면 DC 계수와 같은 주관적 화질 측면에서 중요한 양자화된 계수 를 똑같은 값으로 유지하면서 엔트로피 부호화방법으로 부 호화할 때 효율적으로 부호화 할 수 있게 된다. 양자화의 크기는 식 (1)의 $\mathrm{Q}$ 값을 변화시켜서 조절하였으며 아래 식 (3)와 같이 $\mathrm{Q}$ 값을 조절하여 $\mathrm{Q}^{\prime}$ 로 만들어 양자화 한다.

$$
\begin{aligned}
& Q_{L, Q P \% 6}^{\prime}=Q_{Q P \% 6} \times R_{L} \\
& Q_{C H, Q P \% 6}^{\prime}=Q_{Q P \% 6} \times R_{C H}
\end{aligned}
$$

$\mathrm{QQP} \%$ 는 표. 1에 나와 있는 양자화의 크기를 조절하기 위해 양자화 식 (1)에 쓰이는 값이다. 또한 $\mathrm{Q} ' \mathrm{~L}, \mathrm{QP} \% 6$ 과 $\mathrm{Q}^{\prime} \mathrm{CH}, \mathrm{QP} \% 6$ 는 주사순서상 뒤 쪽의 양자화 된 계수들을 크 게 하기 위해서 식 (1)의 $\mathrm{QQP} \% 6$ 값 대신에 쓸 값들로 $\mathrm{Q} \mathrm{L}, \mathrm{QP} \% 6$ 은 휘도TU의 양자화된 계수에 사용할 값이고 $\mathrm{Q}^{\prime} \mathrm{CH}, \mathrm{QP} \% 6$ 은 색차TU의 양자회된 계수에 사용할 값이다. $\mathrm{R}$ 은 $\mathrm{Q}$ 와 $\mathrm{Q}^{\prime}$ 간의 비율을 뜻한다. $\mathrm{R}$ 이 1 보다 작게 주어지면, 식 (1)에 의하여 기존보다 양자화를 크게 할 수 있다. RL과 $\mathrm{RCH}$ 는 각각 휘도성분과 색차성분의 R값을 뜻한다. 양자화 된 변환계수가 $\mathrm{DC}$ 쪽으로 모이는 정도는 휘도성분보다 색 차성분이 더 강하기 때문에, 휘도TU과 색차TU에 대하여 크기를 다르게 적용하였다. 따라서, $\mathrm{Q}^{\prime}$ 값은 $\mathrm{QP}$ 를 6으로 나 눈 나머지 값에 따라 달라지고, 휘도성분이냐 색차성분이 냐에 따라 다르며, R값에 따라 달라지게 된다.

이에 맞춰서 역 양자화할 때도 제안된 양자화에 맞춰 역 양자화 해야 한다. 그러기 위해서는 $\mathrm{Q}$ 값과 $\mathrm{IQ}$ 값의 관계식 를 알고, 그 관계식에 따라서 $\mathrm{IQ}$ 값을 만들어 역 양자화 할 때, TU내 Q'값으로 양자화한 위치와 똑같은 위치에 IQ'값 으로 식 (2)을 이용하여 역 양자화 해 줘야 한다. 식 (4)는 $\mathrm{Q}$ 값과 IQ값의 관계를 표현하는 식이다. 이 식을 이용하면, $\mathrm{Q}$ 값이 정해지면 이에 맞춰서 $\mathrm{IQ}$ 값도 만들 수 있다.

$$
\begin{aligned}
& I Q^{\prime}{ }_{L, Q P \% 6} \times Q_{L, Q P \% 6}^{\prime}=2^{20} \\
& I Q_{C H, Q P \% 6}^{\prime} \times Q_{C H, Q P \% 6}^{\prime}=2^{20}
\end{aligned}
$$


위의 식에 의하면, $\mathrm{IQ}^{\prime} \mathrm{L}, \mathrm{QP} \%$ 값과 $\mathrm{IQ}^{\prime} \mathrm{CH}, \mathrm{QP} \% 6$ 은 TU 내에서 주사순서상 뒤 쪽의 양자화된 계수를 역양자화 할 때 쓰는 식 (2)의 IQQP\%6값 대신에 들어갈 IQ'값으로 $\mathrm{IQ}^{\prime} \mathrm{L}, \mathrm{QP} \% 6$ 는 휘도 TU에 쓰이고, IQ'CH,QP\%6는 색차TU 에 쓰인다. 역양자화할 때 원래의 양자화하기 전의 변환계 수와 근사한 변환계수로 복원하기 위해서 $\mathrm{Q}$ 값과 $\mathrm{IQ}$ 값의 곱 은 220이 나와야 된다. 이는 양자화 할 때 쓰는 식 (1)과 역양자화 할 때 쓰는 식 (2)를 바탕으로 알 수 있다.

그림 2는 정사각형 모양의 $8 \times 8 \mathrm{TU}$, 비정사각형 $8 \times 2,2 \times 8$ 모양의 TU를 예로 들어 제안된 방법으로 양자화 하는 모양 을 보여준다. 그림 2에 의하면 대각선방향의 주사방식, 가 로방향의 주사방식, 세로방향의 주사방식 그리고 지그재그 주사방식에 따라 다른 형태의 양자화를 하는 것을 보여준
다. 그림 2에 나와 있는 $\mathrm{TU}$ 모양에서 흰 부분은 $\mathrm{Q}$ 값을 이용 하여 양자화를 하는 영역이고 회색 부분은 R값이 곱해 진 $\mathrm{Q}^{\prime}$ 값을 이용하여 양자화를 하는 영역이다. 양자화 하는 영 역을 두 부분으로 나누는 기준은 주사순서상 TU의 가로길 이와 세로길이를 합친 만큼 떨어진 부분까지이다. 예를 들 어, TU의 크기가 $\mathrm{NxM}$ 이라면, 주사순서로 $\mathrm{N}+\mathrm{M}$ 만큼 떨어 진 만큼은 기존과 같은 크기로 양자화를 하고, 그 다음 순서 부터는 제안된 $\mathrm{Q}^{\prime}$ 값이 적용된 기존보다 크게 양자화한다. 이에 따라 역 양자화도 $\mathrm{TU}$ 내 Q값으로 양자화한 영역에는 $\mathrm{IQ}$ 값으로 역양자화 하고, $\mathrm{Q}^{\prime}$ 값으로 양자화한 영역에는 IQ' 값으로 역양자화한다.

그림 3는 제안된 방법이 엔트로피 부호화 측면에서 효율 이 있음을 보여준다. (a)와 같이 주사 순서상 뒤 쪽에 있는
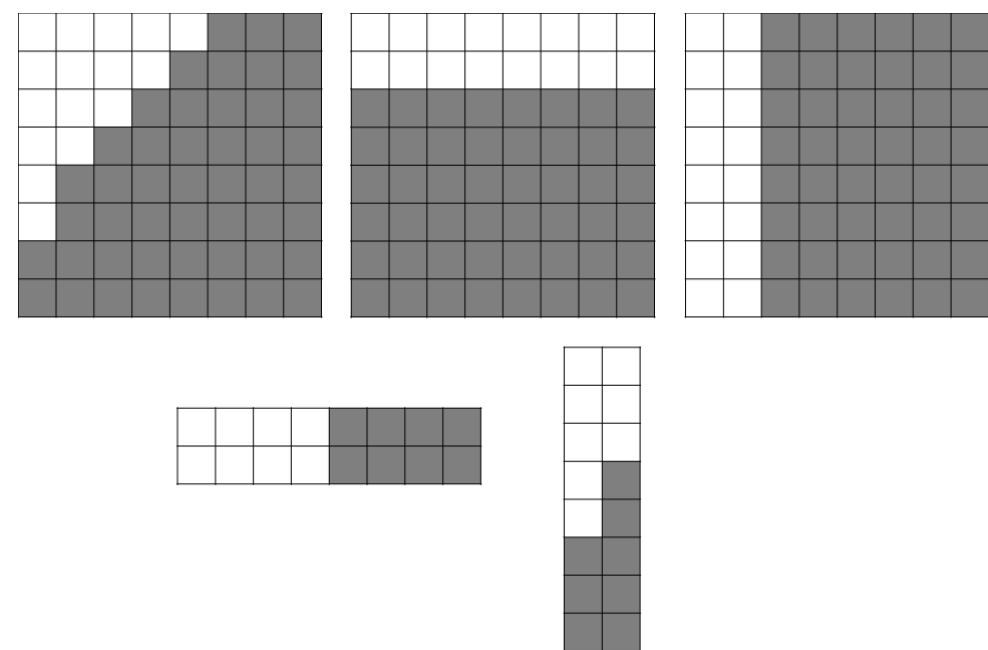

그림 2. 8x8 TU 및 비정사각형 TU에서의 제안된 양자화 방법

Fig. 2. Proposed Quantization in $8 \times 8$ TU and non-square TU

$-10-1011001-4-1100000000-1-10000000000000-100 \ldots$

(a) 기존의 양자화된 계수

(a) Original Quantized Coefficient

$-10-1011001-4-1100000000000000000000000000 \ldots$

(b) 제안된 방법의 양자화된 계수

(b) Proposed Quantized Coefficient

그림 3. 8x8 TU의 주사 선서상의 양자화된 계수

Fig. 3. Quantized Coefficient according to scanning order of $8 \times 8$ TU 
양자화된 계수는 고주파 영역으로 주관적 화질을 표현할 때 다른 계수에 비해서 중요한 정보가 아니다. 하지만 엔트 로피 인코딩 시 중요도가 적은 고주파 영역의 계수를 표현 하기 위해서 실질적으로 많은 비트를 소요한다. HEVC의 엔트로피 부호화의 코딩 기반의 적응적 가변길이 코딩 (CAVLC)의 경우, 블록 내 주사 순서 상 가장 마지막에 오 는 0 이 아닌 계수의 위치를 디코더 측에 보내주고, 0 이 아 닌 계수들 사이의 0 의 개수를 디코더 측에 보내준다. 그렇 게 되면, 높은 주파수 계열의 계수가 매우 적더라도 0 이 아 닌 계수들 사이의 0 의 개수가 많다면 비트율이 늘어날 수도 있다. 이러한 경우가 생기지 않게 하기 위해서, 주사순서상 뒤 쪽에 위치하는 높은 주파수 영역에 해당하는 계수에 대 해서 양자화를 크게 할 필요가 있다.

따라서, 제안된 알고리즘은 $\mathrm{DC}$ 계수와 같은 저주파 영역 의 계수를 그대로 남겨 놓으면서, 고주파영역의 0 이 아닌 계수들 사이의 0 의 개수를 표현하는데 드는 비트 수를 줄이
면서 비트율을 줄일 수 있어 효율적인 코딩을 할 수 있다.

\section{IV. 실험 결과}

\section{1. 실험 조건}

제안된 엔트로피 부호화의 성능을 고려한 비균등 양자화 방법은 $\mathrm{HEVC}$ 참조 소프트 웨어 HM4.0 $\left[{ }^{11}\right.$ 버전에서 구현 하였으며, 실험조건은 $\mathrm{HEVC}$ 의 공통된 실험조건 ${ }^{[15]}$ 과 동일 하게 하였다. 표 2는 High Efficiency와 Low Complexity에 서 사용되는 부호화 기술에 대한 표이다. 엔트로피 부호화 기술은 High Efficiency에서 문맥 기반 적응적 산술코딩 (CABAC : Context-based Adaptive Variable Coding)이 채 택되어 있고, Low Complexity에서는 코딩 기반의 적응적 가변길이 코딩(CAVLC : Context-based Adaptive Variable

표 2. High Efficiency와 Low Complexity에서의 실험 조건

Table 2. Test Conditions of High Efficiency and Low Complexity

\begin{tabular}{|c|c|}
\hline High Efficiency & Low Complexity \\
\hline \multicolumn{2}{|c|}{ Coding Unit $8 \times 8$ up to $64 \times 64$ in tree structure } \\
\hline \multicolumn{2}{|c|}{$\begin{array}{l}\text { Prediction Units } \\
\text { Asymmetric Motion Partition }\end{array}$} \\
\hline \multicolumn{2}{|c|}{$\begin{array}{c}\text { Transform unit tree( } 3 \text { level max) } \\
\text { Transform block size } 4 \times 4 \text { to } 32 \times 32 \text { samples } \\
\text { Mode-dependent Transform for } 4 \times 4 \text { block (DST) } \\
\text { Non-square Quad-tree Transform } \\
\text { Rate Distortion Optimized Quantization }\end{array}$} \\
\hline \multicolumn{2}{|c|}{$\begin{array}{c}\text { Angular Intra Prediction (Max. } 34 \text { directions and Planar mode) } \\
\text { Adaptive Intra Smoothing } \\
\text { Intra Chroma Prediction using Luma samples }\end{array}$} \\
\hline \multicolumn{2}{|c|}{$\begin{array}{l}\text { Luma: } 8 \text {-tap separable DCT-based interpolation filter (1/4-sample) } \\
\text { Chroma: } 4 \text {-tap separable DCT-based interpolation filter with (1/8-sample) }\end{array}$} \\
\hline \multicolumn{2}{|c|}{$\begin{array}{l}\text { Coding Unit based Skip \& Prediction Unit based merging } \\
\text { Advanced motion vector prediction }\end{array}$} \\
\hline CABAC entropy coding & CAVLC \\
\hline Internal bit-depth increase (2 bits) & $x$ \\
\hline \multicolumn{2}{|c|}{$\begin{array}{l}\text { Deblocking filter } \\
\text { Sample Adaptibe Offset }\end{array}$} \\
\hline Adaptive loop filter & $\mathrm{x}$ \\
\hline
\end{tabular}


Length Coding)이 채택되어 있다. 실험 영상으로는 표 3의 $\mathrm{HEVC}$ 실험영상을 사용하였다. $\mathrm{HEVC}$ 에서 기술의 성능 평 가를 위해 권장하는 코딩 구조는 Intra Only, Random Access, Low Delay 이렇게 3가지가 있다. Intra Only 구조 는 모든 프레임이 I픽쳐를 갖는 구조이며, 화면 간 예측은 사용하지 않는 구조이다. 따라서, 그림 2의 제안된 방법 중, 대각선방향의 주사방식, 세로방향의 주사방식, 가로방 향의 주사방식에 적용되는 방법을 사용한다. Random access 구조는 $\mathrm{GOP}$ (Group of pictures)크기가 8 인 계층적 (hierarchical) B픽쳐(IBBBBBBBP)를 갖고 1초마다 I픽쳐 (IDR, Instaneous Decoder Refresh)를 넣는 구조이며, Low delay 구조는 첫 장만이 I픽쳐를 갖는 IPPPPPPPP... 구조이 다. 여기서 $\mathrm{P}$ 픽쳐는 $\mathrm{GPB}($ Generalized P and B picture)이 다. Random access 구조와 Low Delay구조는 화면 간 예측
도 사용하므로, 그림 2 의 제안된 방법을 모두 사용한다. 표 3 의 영상들은 표 4 와 같은 결과가 나오게 하게 위해서 $\mathrm{QP}(\mathrm{Quantization}$ Parameter)값을 22, 27, 32, 37로 두고 실 험하였다. 실험 결과 $\mathrm{RDOQ}$ 를 제외하여 실험했을 때 $\mathrm{RL}=0.9 \mathrm{RCH}=0.7$ 일 때 성능향상이 가장 높았고, $\mathrm{RDOQ}$ 를 제외하지 않고 실험했을 때 $\mathrm{RL}=0.95 \mathrm{RCH}=0.7$ 일 때 성능 향상이 가장 높았다.

\section{2. 실험 결과}

표 4와 표 5는 제안된 방법이 구현되어 있는 HM4.0과 $\mathrm{HM} 4.0$ 과의 성능 비교 결과이다. 표 4 와 표 5 의 $\mathrm{RDOQ}$ off 는 RDOQ 인코더 옵션을 제외한 $\mathrm{HM} 4.0$ 과 제안한 방법과 의 성능 차이이고, $\mathrm{RDOQ}$ off vs RDOQ on은 RDOQ 인코

표 3. 실험용 영상들

Table 3. Test Sequences

\begin{tabular}{|c|c|c|c|}
\hline 클래스 & 영상 명 & 해상도 & 초당 프레임 수 \\
\hline A & Traffic & $2560 \times 1600$ & $30 \mathrm{fps}$ \\
\hline A & PeopleOnStreet & $2560 \times 1600$ & $30 \mathrm{fps}$ \\
\hline A & NebutaFestival & $2560 \times 1600$ & $60 \mathrm{fps}$ \\
\hline A & SteamLocomotiveTrain & $2560 \times 1600$ & $60 \mathrm{fps}$ \\
\hline B & Kimono & $1920 \times 1080$ & $24 \mathrm{fps}$ \\
\hline B & ParkScene & $1920 \times 1080$ & $24 \mathrm{fps}$ \\
\hline B & Cactus & $1920 \times 1080$ & $50 \mathrm{fps}$ \\
\hline B & BasketballDrive & $1920 \times 1080$ & $50 \mathrm{fps}$ \\
\hline B & BQTerrace & $1920 \times 1080$ & $60 \mathrm{fps}$ \\
\hline C & BasketballDrill & $832 \times 480$ & $50 \mathrm{fps}$ \\
\hline C & BQMall & $832 \times 480$ & $60 \mathrm{fps}$ \\
\hline C & PartyScene & $832 \times 480$ & $50 \mathrm{fps}$ \\
\hline C & RaceHorses & $832 \times 480$ & $30 \mathrm{fps}$ \\
\hline D & BasketballPass & $416 \times 240$ & $50 \mathrm{fps}$ \\
\hline D & BQSquare & $416 \times 240$ & $60 \mathrm{fps}$ \\
\hline D & BlowingBubbles & $416 \times 240$ & $50 \mathrm{fps}$ \\
\hline D & RaceHorses & $416 \times 240$ & $30 \mathrm{fps}$ \\
\hline E & Vidyo1 & $1280 \times 720$ & $60 \mathrm{fps}$ \\
\hline E & Vidyo3 & $1280 \times 720$ & $60 \mathrm{fps}$ \\
\hline E & Vidyo4 & \\
\hline
\end{tabular}


표 4. High Efficiency에서의 실험 결과

Table 4. Experimental results in High Efficiency

\begin{tabular}{|c|c|c|c|c|c|c|c|c|c|c|}
\hline & & \multicolumn{3}{|c|}{ RDOQ off } & \multicolumn{3}{|c|}{ RDOQ off vs RDOQ on } & \multicolumn{3}{|c|}{ RDOQ on } \\
\hline & & Y BD-rate & U BD-rate & V BD-rate & Y BD-rate & U BD-rate & V BD-rate & Y BD-rate & U BD-rate & V BD-rate \\
\hline \multirow{6}{*}{$\begin{array}{l}\text { Intra } \\
\text { Only }\end{array}$} & $A$ & $-0.6 \%$ & $-1.3 \%$ & $1.3 \%$ & $-5.3 \%$ & $0.8 \%$ & $2.5 \%$ & $-0.12 \%$ & $0.46 \%$ & $1.21 \%$ \\
\hline & B & $-0.6 \%$ & $-2.1 \%$ & $-2.4 \%$ & $-6.5 \%$ & $-0.4 \%$ & $-0.4 \%$ & $0.01 \%$ & $0.31 \%$ & $0.31 \%$ \\
\hline & C & $-0.6 \%$ & $-0.6 \%$ & $-1.5 \%$ & $-5.0 \%$ & $0.4 \%$ & $-0.5 \%$ & $-0.08 \%$ & $0.67 \%$ & $0.22 \%$ \\
\hline & $\mathrm{D}$ & $-0.4 \%$ & $-1.5 \%$ & $-1.4 \%$ & $-4.9 \%$ & $1.9 \%$ & $0.8 \%$ & $-0.02 \%$ & $0.18 \%$ & $0.18 \%$ \\
\hline & E & $-0.1 \%$ & $-3.2 \%$ & $-3.0 \%$ & $-4.8 \%$ & $-0.3 \%$ & $-0.9 \%$ & $0.06 \%$ & $-0.50 \%$ & $-0.41 \%$ \\
\hline & average & $-0.5 \%$ & $-1.7 \%$ & $-1.4 \%$ & $-5.4 \%$ & $0.5 \%$ & $0.3 \%$ & $-0.03 \%$ & $0.26 \%$ & $0.34 \%$ \\
\hline \multirow{5}{*}{$\begin{array}{l}\text { Random } \\
\text { Access }\end{array}$} & $A$ & $-0.7 \%$ & $1.5 \%$ & $3.9 \%$ & $-5.0 \%$ & $-4.3 \%$ & $-4.5 \%$ & $-0.12 \%$ & $2.30 \%$ & $4.17 \%$ \\
\hline & B & $-0.3 \%$ & $0.0 \%$ & $0.0 \%$ & $-5.3 \%$ & $-6.4 \%$ & $-5.8 \%$ & $-0.02 \%$ & $0.94 \%$ & $0.93 \%$ \\
\hline & C & $0.1 \%$ & $0.4 \%$ & $0.2 \%$ & $-5.0 \%$ & $-7.1 \%$ & $-7.2 \%$ & $0.05 \%$ & $1.35 \%$ & $0.95 \%$ \\
\hline & D & $0.1 \%$ & $0.2 \%$ & $-0.1 \%$ & $-4.8 \%$ & $-5.4 \%$ & $-5.6 \%$ & $0.07 \%$ & $0.84 \%$ & $0.29 \%$ \\
\hline & average & $-0.2 \%$ & $0.5 \%$ & $0.9 \%$ & $-5.1 \%$ & $-5.8 \%$ & $-5.8 \%$ & $-0.01 \%$ & $1.33 \%$ & $1.55 \%$ \\
\hline \multirow{5}{*}{$\begin{array}{l}\text { Low } \\
\text { Delay }\end{array}$} & B & $-0.4 \%$ & $-0.9 \%$ & $-1.3 \%$ & $-4.1 \%$ & $-5.5 \%$ & $-4.8 \%$ & $-0.02 \%$ & $0.83 \%$ & $-0.17 \%$ \\
\hline & C & $-0.1 \%$ & $-0.2 \%$ & $-0.5 \%$ & $-3.6 \%$ & $-5.4 \%$ & $-5.4 \%$ & $-0.03 \%$ & $0.67 \%$ & $0.25 \%$ \\
\hline & D & $0.0 \%$ & $-0.7 \%$ & $-1.1 \%$ & $-3.6 \%$ & $-5.9 \%$ & $-5.7 \%$ & $-0.04 \%$ & $0.41 \%$ & $0.41 \%$ \\
\hline & $\mathrm{E}$ & $0.0 \%$ & $-2.1 \%$ & $-1.5 \%$ & $-1.8 \%$ & $-3.4 \%$ & $-1.9 \%$ & $0.11 \%$ & $-1.32 \%$ & $-0.10 \%$ \\
\hline & average & $-0.1 \%$ & $-0.9 \%$ & $-1.1 \%$ & $-3.4 \%$ & $-5.2 \%$ & $-4.6 \%$ & $0.00 \%$ & $0.28 \%$ & $0.09 \%$ \\
\hline
\end{tabular}

표 5. Low Complexity에서의 실험결과

Table 5. Experimental results in Low Complexity

\begin{tabular}{|c|c|c|c|c|c|c|c|c|c|c|}
\hline & & \multicolumn{3}{|c|}{ RDOQ off } & \multicolumn{3}{|c|}{ RDOQ off vs RDOQ on } & \multicolumn{3}{|c|}{ RDOQ on } \\
\hline & & Y BD-rate & U BD-rate & V BD-rate & Y BD-rate & U BD-rate & V BD-rate & Y BD-rate & U BD-rate & V BD-rate \\
\hline \multirow{6}{*}{$\begin{array}{l}\text { Intra } \\
\text { Only }\end{array}$} & A & $-0.6 \%$ & $-2.2 \%$ & $-1.1 \%$ & $-5.4 \%$ & $-4.5 \%$ & $-4.3 \%$ & $-0.05 \%$ & $-0.20 \%$ & $0.21 \%$ \\
\hline & B & $-1.0 \%$ & $-2.8 \%$ & $-2.9 \%$ & $-7.6 \%$ & $-6.9 \%$ & $-7.3 \%$ & $0.02 \%$ & $0.12 \%$ & $0.10 \%$ \\
\hline & C & $-0.7 \%$ & $-0.9 \%$ & $-1.6 \%$ & $-5.3 \%$ & $-4.1 \%$ & $-5.0 \%$ & $-0.06 \%$ & $0.57 \%$ & $0.37 \%$ \\
\hline & D & $-0.5 \%$ & $-1.6 \%$ & $-1.2 \%$ & $-5.0 \%$ & $-3.0 \%$ & $-3.9 \%$ & $-0.04 \%$ & $0.29 \%$ & $0.54 \%$ \\
\hline & $\mathrm{E}$ & $-0.4 \%$ & $-3.5 \%$ & $-3.2 \%$ & $-5.2 \%$ & $-10.0 \%$ & $-9.9 \%$ & $0.00 \%$ & $-0.42 \%$ & $-0.37 \%$ \\
\hline & average & $-0.7 \%$ & $-2.1 \%$ & $-2.0 \%$ & $-5.8 \%$ & $-5.6 \%$ & $-6.0 \%$ & $-0.02 \%$ & $0.10 \%$ & $0.19 \%$ \\
\hline \multirow{5}{*}{$\begin{array}{l}\text { Rando } \\
\mathrm{m} \\
\text { Access }\end{array}$} & A & $-0.5 \%$ & $1.4 \%$ & $2.4 \%$ & $-4.0 \%$ & $-8.8 \%$ & $-9.8 \%$ & $-0.13 \%$ & $1.47 \%$ & $2.53 \%$ \\
\hline & B & $-0.4 \%$ & $-0.6 \%$ & $-0.5 \%$ & $-5.0 \%$ & $-11.7 \%$ & $-11.9 \%$ & $-0.03 \%$ & $0.80 \%$ & $0.69 \%$ \\
\hline & C & $0.0 \%$ & $0.2 \%$ & $0.0 \%$ & $-4.8 \%$ & $-11.1 \%$ & $-11.3 \%$ & $-0.01 \%$ & $1.06 \%$ & $0.75 \%$ \\
\hline & D & $0.0 \%$ & $-0.2 \%$ & $0.3 \%$ & $-4.9 \%$ & $-11.1 \%$ & $-11.3 \%$ & $-0.03 \%$ & $0.76 \%$ & $0.99 \%$ \\
\hline & average & $-0.2 \%$ & $0.2 \%$ & $0.5 \%$ & $-4.7 \%$ & $-10.7 \%$ & $-11.1 \%$ & $-0.05 \%$ & $1.01 \%$ & $1.20 \%$ \\
\hline \multirow{5}{*}{$\begin{array}{l}\text { Low } \\
\text { Delay }\end{array}$} & B & $-0.5 \%$ & $-0.9 \%$ & $-1.5 \%$ & $-3.4 \%$ & $-10.7 \%$ & $-11.8 \%$ & $-0.09 \%$ & $0.86 \%$ & $0.61 \%$ \\
\hline & C & $-0.3 \%$ & $-0.3 \%$ & $-0.8 \%$ & $-3.4 \%$ & $-9.6 \%$ & $-9.6 \%$ & $-0.11 \%$ & $1.02 \%$ & $0.29 \%$ \\
\hline & D & $-0.2 \%$ & $-1.1 \%$ & $-0.7 \%$ & $-3.4 \%$ & $-11.7 \%$ & $-11.6 \%$ & $-0.09 \%$ & $0.43 \%$ & $0.38 \%$ \\
\hline & $\mathrm{E}$ & $-0.2 \%$ & $-2.4 \%$ & $-1.1 \%$ & $-2.0 \%$ & $-11.2 \%$ & $-8.1 \%$ & $-0.02 \%$ & $-0.53 \%$ & $0.24 \%$ \\
\hline & average & $-0.3 \%$ & $-1.1 \%$ & $-1.0 \%$ & $-3.2 \%$ & $-10.8 \%$ & $-10.5 \%$ & $-0.08 \%$ & $0.53 \%$ & $0.40 \%$ \\
\hline
\end{tabular}


더 옵션을 제외했을 때와 RDOQ 를 제외하지 않았을 때 $\mathrm{HM} 4.0$ 의 성능 차이이다. RDOQ 알고리즘을 바탕으로 제안된 방법을 적용할 수 있다. 따라서, 표 4와 표 5 의 $\mathrm{RDOQ}$ on은 $\mathrm{RDOQ}$ 에 제안한 방법을 적용한 $\mathrm{HM} 4.0$ 과 $\mathrm{HM} 4.0$ 의 성능 차이이다. 표 4에 나타나 있는 BD-rate는 VCEG-M $33^{[16]}$ 에 정의되어 있으며, 율-왜곡 곡선 상에서의 평균 비트율 증가량을 나타낸다. 따라서 BD-rate가 음수일 때 압축률이 향상되었다고 평가할 수 있다. 또한 표 4는 High Efficiency구조에서의 실험결과이고, 표 5는 Low Complexity에서의 실험 결과이다.

$\mathrm{RDOQ}$ off 실험 결과로 Intra Only 구조에서 가장 성능이 높게 나왔으며, 이 때 Y BD-rate는 High Efficiency에서 $-0.5 \%$ 가 나왔고, Low Complexity에서 $-0.7 \%$ 가 나왔다. 또 한 Intra Only 구조에서 색차성분에서는 $-1.4 \%$ 에서 $-2.1 \%$ 까지의 BD-rate가 나왔다. 실험 결과를 보면 Random Access 구조를 제외하고는 휘도 성분보다는 대체로 에너지 가 낮고 저 주파수 영역이 많은 색차성분에서 압축률이 더
향상되었다. 또한 해상도가 높은 영상인 $\mathrm{A}$ 클래스와 $\mathrm{B}$ 클래 스에서 성능이 가장 높게 나오는 것을 확인할 수 있다.

$\mathrm{RDOQ}$ on 실험 결과에 의하면, 제안된 방법을 적용해도 성능에 차이가 없다. 앞에서 언급했듯이, $\mathrm{RDOQ}$ 란 $\mathrm{TU}$ 내 한 계수를 양자화 할 때, 다수의 계수 후보를 두고 에러 값 과 엔트로피 코딩을 고려한 비트 수를 계산하여 율 왜곡 값이 가장 낮은 계수를 쓰는 방식이다. RDOQ off vs $\mathrm{RDOQ}$ on에서 확인할 수 있듯이 $\mathrm{RDOQ}$ 는 성능이 좋으나 복잡도가 많이 증가한다. $\mathrm{RDOQ}$ 에 의해 증가된 부호화시 간은 표 5 에서 확인할 수 있다. 즉, $\mathrm{TU}$ 속의 모든 양자화된 계수를 율 왜곡 최적화시키기 때문에 이미 제안된 방법에 서 의도했던 PSNR대비 최소의 비트를 사용하게 되어 있으 며, 여기서 제안된 방법을 적용해도 압축률에서 차이가 없 다.

표 6와 표 7은 각각 부호화 시간과 복호화 시간을 제안한 방법과 참조 소프트웨어 HM4.0과 비교한 표이다. $\Delta \mathrm{T}$ 는 참 조 소프트웨어와 제안된 방법간의 부호화 혹은 복호화 시

표 6. 부호화 시간 $\Delta \mathrm{T}$

Table 6. Encoding Time $\Delta \mathrm{T}$

\begin{tabular}{|c|c|c|c|c|c|c|}
\hline \multirow{2}{*}{$\Delta \mathrm{T}(\%)$} & \multicolumn{2}{|c|}{$\mathrm{RDOQ}$ off } & RDOQ off vs RDOQ on & \multicolumn{2}{c|}{ RDOQ on } \\
\hline & $\begin{array}{c}\text { High } \\
\text { Efficiency }\end{array}$ & $\begin{array}{c}\text { Low } \\
\text { Complexity }\end{array}$ & $\begin{array}{c}\text { High } \\
\text { Efficiency }\end{array}$ & $\begin{array}{c}\text { Low } \\
\text { Complexity }\end{array}$ & $\begin{array}{c}\text { High } \\
\text { Efficiency }\end{array}$ & $\begin{array}{c}\text { Low } \\
\text { Complexity }\end{array}$ \\
\hline Intra Only & $100 \%$ & $101 \%$ & $117 \%$ & $119 \%$ & $101 \%$ & $101 \%$ \\
\hline Random Access & $100 \%$ & $100 \%$ & $125 \%$ & $142 \%$ & $99 \%$ & $102 \%$ \\
\hline Low Delay & $101 \%$ & $100 \%$ & $153 \%$ & $128 \%$ & $99 \%$ & $100 \%$ \\
\hline Average & $100 \%$ & $100 \%$ & $132 \%$ & $130 \%$ & $100 \%$ & $101 \%$ \\
\hline
\end{tabular}

표 7. 복호화 시간 $\Delta T$

Table 7. Decoding Time $\Delta \mathrm{T}$

\begin{tabular}{|c|c|c|c|c|}
\hline$\Delta \mathbf{T}(\%)$ & \multicolumn{2}{|c|}{ RDOQ off } & \multicolumn{2}{c|}{ RDOQ on } \\
\hline & High Efficiency & Low Complexity & High Efficiency & Low Complexity \\
\hline Intra Only & $101 \%$ & $101 \%$ & $102 \%$ & $102 \%$ \\
\hline Random Access & $100 \%$ & $100 \%$ & $101 \%$ & $101 \%$ \\
\hline Low Delay & $100 \%$ & $100 \%$ & $101 \%$ & $101 \%$ \\
\hline Average & $100 \%$ & $100 \%$ & $101 \%$ & $101 \%$ \\
\hline
\end{tabular}


간의 비율이며 아래 식 (5)에서 표현할 수 있다. 또한 $\mathrm{RDOQ}$ 는 인코더 옵션이므로, 역양자화 방법은 $\mathrm{RDOQ}$ 를 제외시켰을 경우와 같으므로, 복호화시간 또한 $\mathrm{RDOQ}$ 를 제외시킨 것과 같다. 표 6의 RDOQ off vs RDOQ on의 결 과를 보면, RDOQ가 표 4와 표 5의 RDOQ off vs RDOQ on의 실험결과 같은 성능을 내기 위해서 부호화 시간을 많 이 증가시킴을 알 수 있다. $\mathrm{RDOQ}$ 는 평균 $31 \%$ 정도 부호화 시간을 증가시킨다. 반면에, 표 6와 표 7에서 제안된 방법의 부호화시간과 복호화 시간은 RDOQ off와 RDOQ on 모두 참조 소프트웨어와 비슷다는 것을 알 수 있다. 따라서, 제안 된 알고리즘은 전체적인 부호화 혹은 복호화 시간을 증가 시키지 않으면서 전체적인 $\mathrm{BD}-\mathrm{rate}$ 를 감소시키며 부호화 성능을 향상시켰다.

$$
\Delta T=\frac{T_{\text {proposed }}}{T_{\text {referenced }}} \times 100(\%)
$$

\section{V. 결 론}

제안된 엔트로피 부호화를 고려한 양자화 방법은 주사 순서상 뒤쪽에 있는 양자화된 계수에 더 큰 양자화를 하여 작은 에너지를 가지고 있는 계수를 제거함으로써 엔트로피 부호화의 효율을 높인다. 제안된 방법을 HM4.0에 적용시 켰을 때, 휘도 성분에서는 최대 BD-rate가 최대 $-0.7 \%$ 정 도의 성능향상, 색차 성분에서는 최대 $-2.1 \%$ 까지의 $\mathrm{BD}-$ rate 성능 향상을 얻었고 부호화시간과 복호화시간은 $100 \%$ 유지한다. 따라서, 제안된 방법은 압축 성능과 저복잡도 부 호화를을 요구하는 응용분야에서 유용하게 사용될 수 있을 것으로 예상된다.

\section{참 고 문 헌}

[1] Benjamin Bross, Woo-Jin Han, Jens-Rainer Ohm, Gary J. Sullivan, Thomas Wiegand, "WD4: Working Draft 4 of High-Efficiency Video Coding", document JCTVC-F803, July, 2011.

[2] Frank Bossen, TK Tan, Junya Takiue, "Simplified angular intra prediction", document JCTVC-B093, July, 2010.

[3] Ken McCann, et al, " Samsung's Response to the Call for Proposals on Video Compression Technology", document JCTVC-A124, April, 2010

[4] Hiroya Nakamura, Shigeru Fukushima, Masayoshi Nishitani, "Unification of derivation process for merge mode and MVP", document JCTVC-F419, July, 2011

[5] Kemal Ugur, Kenneth R. Andersson, Arild Fuldseth, "Description of video coding technology proposal by Tandberg, Nokia, Ericsson", document JCTVC-A119, April, 2010.

[6] T. Chujoh, R. Noda, "Internal bit depth increase for coding efficiency", ITU-T SG16 Q.6 document VCEG-AE13, January, 2007.

[7] T. Chujoh, R. Noda, "Internal bit depth increase except frame memory", ITU-T SG16 Q.6 document VCEG-AF07, April, 2007.

[8] M. Karczewicz, Y. Ye, I. Chong, "Rate distortion optimized quantization," ITU T SG16/Q.6, document VCEG AH21, January, 2008.

[9] T. Chujoh, A. Tanizawa and T. Yamakage, "Adaptive Loop Filter for Improving Coding Efficiency", ITU-T SG16 contribution, C402, April, 2008

[10] Ryeong Hee Gweon, Yung-Lyul Lee, " Early Termination of CU Encoding to Reduce HEVC Complexity ", document JCTVC-F045, July, 2011.

[11] http://hevc.kw.bbc.co.uk/trac/browser/jctvc-hm/tags/HM-4.0

[12] A. Fuldseth, G. Bjøntegaard, M. Sadafale, M. Budagavi, "Transform design for HEVC with 16 bit intermediate data representation", document JCTVC-E243, March, 2011.

[13] Vivienne Sze, Madhukar Budagavi, "CE11: Parallelization of HHI_TRANSFORM_CODING (Fixed Diagonal Scan from C227)", document JCTVC-F129, July, 2011.

[14] Chuohao Yeo, Yih Han Tan, Zhengguo Li, "Mode-Dependent Coefficient Scanning for Intra Prediction Residual Coding", document JCTVC-D049, Jan, 2011.

[15] Frank Bossen, "Common test conditions and software reference configurations", document JCTVC-F900, July, 2011.

[16] Gisle Bjontegarrd, "Calculation of Average PSNR Differences between RD curves", document VCEG-M33, April, 2001. 
저 자 소 개

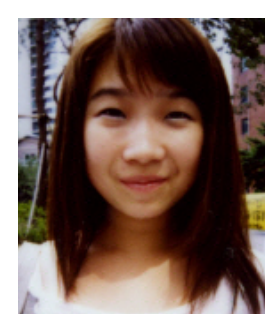

권 령 희

- 2011년 2월 : 세종대학교 컴퓨터공학과(학사)

- 현재 : 세종대학교 컴퓨터공학과(석사과정)

- 주관심분야 : 영상압축, H.264/AVC, HEVC

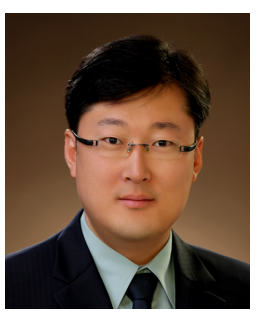

한 우 진

- 1995년 2월 : KAIST 전산학과 공학사

- 1997년 2월 : KAIST 전산학과 공학석사

- 2002년 2월 : KAIST 전산학과 공학박사

- 2002년 3월 2003년 3월 : SL2 연구소장

- 2003년 4월 2011년 8월 : 삼성전자 DMC 연구소 수석연구원

- 2011년 9월 현재 : 경원대학교 소프트웨어설계경영학과 교수

- 주관심분야 : 영상압축, 영상이해, 멀티미디어통신

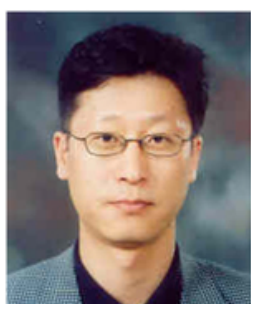

이 영 렬

- 1985년 2월 : 서강대학교 전자공학과(학사)

- 1987년 2월 : 서강대학교 전자공학과(석사)

- 1999년 2월 : KAIST 전기 및 전자공학과(박사)

- 1987년 1월 1994년 2월 : 삼성전자 중앙연구소 DMS Lab. 선임연구원

- 1999년 3월 2001년 8월 : 삼성전자 중앙연구소 DMS Lab. 수석연구원

- 2001년 9월 현재 : 세종대학교 컴퓨터공학부 컴퓨터공학과 교수

- 주관심분야 : 영상처리(압축,복원), 영상전송, 멀티미디어 시스템, 3 차원 비디오코딩, 트랜스코딩, Scalable 비디오 코딩 